\title{
Front Matter: Volume 6881
}

, "Front Matter: Volume 6881," Proc. SPIE 6881, Commercial and Biomedical Applications of Ultrafast Lasers VIII, 688101 (13 March 2008); doi:

10.1117/12.796306

EDIE Event: Lasers and Applications in Science and Engineering, 2008, San Jose, California, United States 


\title{
PROCEEDINGS OF SPIE
}

\section{Commercial and Biomedical Applications of Ultrafast Lasers VIII}

\author{
Joseph Neev \\ Stefan Nolte \\ Alexander Heisterkamp \\ Christopher B. Schaffer \\ Editors
}

20-23 January 2008

San Jose, California, USA

Sponsored by

SPIE

\section{Cosponsored by}

Amplitude Systèmes (France)

Coherent, Inc. (USA)

IMRA America, Inc. (USA)

Spectra-Physics Lasers, Inc. (USA)

Time-Bandwidth Products, Inc. (Switzerland)

Published by

SPIE 
The papers included in this volume were part of the technical conference cited on the cover and title page. Papers were selected and subject to review by the editors and conference program committee. Some conference presentations may not be available for publication. The papers published in these proceedings reflect the work and thoughts of the authors and are published herein as submitted. The publisher is not responsible for the validity of the information or for any outcomes resulting from reliance thereon.

Please use the following format to cite material from this book:

Author(s), "Title of Paper," in Commercial and Biomedical Applications of Ultrafast Lasers VIII, edited by Joseph Neev, Stefan Nolte, Alexander Heisterkamp, Christopher B. Schaffer, Proceedings of SPIE Vol. 6881 (SPIE, Bellingham, WA, 2008) Article CID Number.

ISSN 0277-786X

ISBN 9780819470560

Published by

SPIE

P.O. Box 10, Bellingham, Washington 98227-0010 USA

Telephone +1 3606763290 (Pacific Time) · Fax +1 3606471445

SPIE.org

Copyright (c) 2008, Society of Photo-Optical Instrumentation Engineers

Copying of material in this book for internal or personal use, or for the internal or personal use of specific clients, beyond the fair use provisions granted by the U.S. Copyright Law is authorized by SPIE subject to payment of copying fees. The Transactional Reporting Service base fee for this volume is $\$ 18.00$ per article (or portion thereof), which should be paid directly to the Copyright Clearance Center (CCC), 222 Rosewood Drive, Danvers, MA 01923. Payment may also be made electronically through CCC Online at copyright.com. Other copying for republication, resale, advertising or promotion, or any form of systematic or multiple reproduction of any material in this book is prohibited except with permission in writing from the publisher. The CCC fee code is 0277-786X/08/\$18.00.

Printed in the United States of America.

Publication of record for individual papers is online in the SPIE Digital Library.

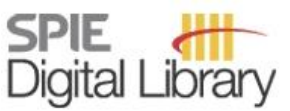

SPIEDigitalLibrary.org

Paper Numbering: Proceedings of SPIE follow an e-First publication model, with papers published first online and then in print and on CD-ROM. Papers are published as they are submitted and meet publication criteria. A unique, consistent, permanent citation identifier (CID) number is assigned to each article at the time of the first publication. Utilization of CIDs allows articles to be fully citable as soon they are published online, and connects the same identifier to all online, print, and electronic versions of the publication. SPIE uses a six-digit CID article numbering system in which:

- The first four digits correspond to the SPIE volume number.

- The last two digits indicate publication order within the volume using a Base 36 numbering system employing both numerals and letters. These two-number sets start with 00, 01, 02, 03, 04, 05, $06,07,08,09,0 \mathrm{~A}, 0 \mathrm{~B} \ldots \mathrm{OZ}$, followed by 10-1Z, 20-2Z, etc.

The CID number appears on each page of the manuscript. The complete citation is used on the first page, and an abbreviated version on subsequent pages. Numbers in the index correspond to the last two digits of the six-digit CID number. 


\section{Contents}

vii Conference Committee

ix The long journey from idea to industrial success (Plenary Paper) [6874-26]

H. Schlüter, TRUMPF Inc. (USA)

\section{ULTRAFAST LASERS IN CELL BIOLOGY}

688104 Numerical modeling of nonlinear plasma formation in high-NA micromachining of transparent materials and biological cells using ultrashort laser pulses [6881-03] C. L. Arnold, A. Heisterkamp, Laser Zentrum Hannover e.V. (Germany); W. Ertmer, Univ. Hannover (Germany); H. Lubatschowski, Laser Zentrum Hannover e.V. (Germany)

ULTRAFAST LASERS IN IMAGING

688106 Femtosecond laser microsurgery system controlled by optical coherence tomography [6881-04]

O. Massow, Laser Zentrum Hannover e.V. (Germany); F. Will, Rowiak GmbH (Germany);

H. Lubatschowski, Laser Zentrum Hannover e.V. (Germany) and Rowiak GmbH (Germany)

688108 Ultrafast $\mathrm{Yb}: \mathrm{KGd}\left(\mathrm{WO}_{4}\right)_{2}$ laser for multimodal biomedical imaging with reduced photodamage [6881-06]

A. Major, Univ. of Manitoba (Canada) and Univ. of Toronto (Canada); R. Cisek, A. Tuer, N. Prent, V. Barzda, Univ. of Toronto (Canada)

\section{LASER-PLASMA-ACCELERATOR}

688109 Laser-plasma generated very high energy electrons in radiation therapy of the prostate (Invited Paper) [6881-07]

C. DesRosiers, V. Moskvin, M. Cao, Indiana Univ. (USA); C. J. Joshi, Univ. of California, Los Angeles (USA); M. Langer, Indiana Univ. (USA)

6881 OB Medical applications with electron beam generated by laser plasma accelerators (Invited Paper) [6881-09]

V. Malka, J. Faure, Y. Glinec, C. Rechatin, Lab. d'Optique Appliquée, Ecole Nationale Supérieure de Techniques Avancées (France); T. Fuchs, U. Oelfke, H. Szymanowski, German Cancer Research Ctr. (Germany)

\section{LASER VACUUM ACCELERATOR}

6881 OD Optical passive and active acceleration structures: a tutorial (Invited Paper) [6881-11]

L. Schächter, Technion-Israel Institute of Technology (Israel) 
6881 OE First experimental evidence for PASER: particle acceleration by stimulated emission of radiation (Invited Paper) [6881-12]

S. Banna, Applied Materials, Inc. (USA); V. Berezovsky, L. Schächter, Technion-Israel Institute of Technology (Israel)

\section{NOVEL ULTRAFAST LASER SOURCES}

6881 OF Recirculation injection by nonlinear gating for high-power laser pulses (Invited Paper) [6881-14]

I. Jovanovic, Purdue Univ. (USA); M. Shverdin, D. Gibson, C. Brown, Lawrence Livermore National Lab. (USA)

$68810 G$ Parabolic fiber amplifier beyond the gain bandwidth limits [6881-15]

Y. Zaouter, Amplitude Systèmes (France); D. N. Papadopoulos, M. Hanna, F. Druon, Institut d'Optique, CNRS, Univ. Paris Sud (France); E. Mottay, E. Cormier, Univ. de Bordeaux I (France); P. Georges, Institut d'Optique, CNRS, Univ. Paris Sud (France)

$6881 \mathrm{OH}$ Industrial ultrafast internal engraving laser system for anti-counterfeiting applications [6881-16]

E. Mottay, Amplitude Systèmes (France); A. Kupisiewicz, Lasea (Belgium); G. Detroux, KST (Belgium); X. Costet, Costet S.A. (France); A. Simmons, TBS (United Kingdom); U. Vivarelli, SOLOS (Italy); P. Lemaire, Ctr. Spatial de Liège (Belgium); J. Lopez, Univ. Bordeaux (France)

6881 0l Sub picosecond CPA-free high-power ultrafast regenerative amplifier [6881-17] M. Delaigue, A. Courjaud, C. Hoenninger, E. Mottay, Amplitude Systèmes (France)

\section{NOVEL ULTRAFAST LASER SOURCES II}

6881 0J Ultrafast amplified fiber laser for laser-wire measurements in particle accelerators [6881-18] Y. Zaouter, E. Mottay, Amplitude Systèmes (France); L. Corner, N. Delerve, Univ. of Oxford (United Kingdom)

6881 OK Everything you've always wanted to know about an ultrashort pulse but thought was immeasurable (Invited Paper) [6881-19]

R. Trebino, P. Gabolde, P. Bowlan, S. Akturk, Georgia Institute of Technology (USA)

688100 Electronically controlled optical sampling using $100 \mathrm{MHz}$ repetition rate fiber lasers [6881-23]

F. Tauser, C. Rausch, J. H. Posthumus, F. Lison, TOPTICA Photonics AG (Germany)

PHOTONIC DEVICES: JOINT SESSION WITH CONFERENCE 6879A

6881 OU Three-dimensional integration of micro-optics in bulk silica glass by femtosecond laser direct writing: potential for industrial applications [6881-31]

T. Nakaya, D. Shibata, Y. Hatazawa, K. Sunakawa, Y. Yaguchi, Namiki Precision Jewel Co., Ltd. (Japan); K. Hirao, Kyoto Univ. (Japan) 
OPTICAL WAVEGUIDES: JOINT SESSION WITH CONFERENCE 6879A

6881 OV Ultrafast laser microwelding for transparent and heterogeneous materials (Invited Paper) [6881-32]

K. Itoh, Osaka Univ. (Japan); T. Tamaki, Osaka Univ. (Japan) and Nara National College of Technology (Japan)

$6881 \mathrm{OW}$ Influence of the beam-focus size on femtosecond laser-induced damage threshold in fused silica [6881-33]

N. Sanner, Lab. LP3 (France); B. Bussiere, Lab. LP3 (France), Amplitude Technologies (France), and Domaine Univ. de St-Jérôme (France); O. Utéza, A. Leray, T. Itina, M. Sentis, Lab. LP3 (France); J. Y. Natoli, M. Commandré, Domaine Univ. de St-Jérôme (France)

6881 OY Characterization of fused silica specimens exposed to low-energy femtosecond laser pulses using a sub-micron resolution, thermal technique [6881-35]

Y. Bellouard, Eindhoven Univ. of Technology (Netherlands); A. A. Said, M. Dugan, P. Bado, Translume (USA)

$68810 Z$ Delivery of femtosecond pulses by hollow-core optical fiber [6881-61]

Y. Matsuura, Tohoku Univ. (Japan)

\section{OPTICAL WAVEGUIDES II}

688110 Mask-less lithography for fabrication of optical waveguides [6881-36]

M. Dubov, S. R. Natarajan, J. A. R. Williams, I. Bennion, Aston Univ. (United Kingdom)

688111 Structural modifications in Er-Yb doped phosphate glass induced by femtosecond laser waveguide writing [6881-37]

L. B. Fletcher, J. J. Witcher, W. J. Reichman, Univ. of California/Davis (USA); J. Bovatsek, A. Arai, IMRA America, Inc. (USA); D. M. Krol, Univ. of California/Davis (USA)

688112 Efficient second harmonic generation in femtosecond laser written optical waveguides on periodically poled lithium niobate [6881-38]

R. Osellame, N. Chiodo, M. Lobino, M. Marangoni, G. Cerullo, R. Ramponi, IFN-CNR, Politecnico di Milano (Italy); H. T. Bookey, R. R. Thomson, N. Psaila, A. K. Kar, Heriot-Watt Univ. (United Kingdom)

688113 Inscription and characterization of micro-structures in silicate, Foturan and tellurite glasses by femtosecond laser direct writing [6881-40]

K. C. Vishnubhatla, S. Venugopal Rao, R. Sai Santosh Kumar, Univ. of Hyderabad (India):

K. Shiva Prasad, P. S. R. Prasad, National Geophysical Research Institute (India);

D. Narayana Rao, Univ. of Hyderabad (India) 
688114 Micro-Raman mapping of micro-gratings in Baccarat glass directly written using femtosecond laser [6881-41]

K. C. Vishnubhatla, Univ. of Hyderabad (India), Univ. di Trento (Italy), and IFN, CNR, INFM (Italy); S. Venugopal Rao, R. Sai Santosh Kumar, Univ. of Hyderabad (India);

S. N. B. Bhaktha, Univ. des Sciences et Technologies de Lille (France); A. Chiappini,

A. Chiasera, Univ. di Trento (Italy); J. Laureyns, Univ. des Sciences et Technologies de Lille (France); M. Ferrari, IFN-CNR (Italy); M. Mattarelli, M. Montagna, Univ. di Trento (Italy); R. Osellame, R. Ramponi, IFN, CNR, INFM (Italy); G. C. Righini, Nello Carrara Istitute of Applied Physics, IFAC-CNR (Italy); S. Turrell, Univ. des Sciences et Technologies de Lille (France); D. Narayana Rao, Univ. of Hyderabad (India)

\section{SURFACE STRUCTURING FOR PHOTOVOLTAICS AND ENHANCED DETECTION}

688117 Selective structuring of thin-film solar cells by ultrafast laser ablation (Invited Paper) [6881-45]

H. P. Huber, F. Herrnberger, S. Kery, Munich Univ. of Applied Sciences (Germany); S. Zoppel, Vorarlberg Univ. of Applied Sciences (Austria)

688119 Femtosecond laser for black silicon and photovoltaic cells (Invited Paper) [6881-47] T. Sarnet, LP3 (France); M. Halbwax, ICMPE (France); R. Torres, P. Delaporte, M. Sentis, LP3 (France); S. Martinuzzi, TECSEN (France); V. Vervisch, F. Torregrosa, H. Etienne, L. Roux, IBS (France); S. Bastide, ICMPE (France)

\section{MICROMACHINING}

6881 1B Efficient micro machining with high average power picosecond lasers [6881-49] S. Weiler, U. Stute, S. Massa, S. Buettner, B. Faisst, TRUMPF Laser GmbH + Co. KG (Germany)

6881 1D Ultrafast laser induced controllable jet in liquid [6881-51]

S. Oshemkov, Pixer Technology (Israel); L. Dvorkin, Lasermax Engineering Ltd. (Israel);

V. Dmitriev, Pixer Technology (Israel)

6881 1G Processing of natural diamond using nanosecond and picosecond lasers: relative merits and demerits [6881-62]

S. K. Sudheer, Vellore Institute of Technology (India); B. Kakadia, Sheetal Manufacturing Co. (India); V. P. M. Pillai, Univ. of Kerala (India); G. A. Shafeev, A. V. Simakin, Prokhorov

General Physics Institute (Russia)

Author Index 


\title{
Conference Committee
}

\author{
Symposium Chairs \\ Henry Helvajian, The Aerospace Corporation (USA) \\ Friedrich G. Bachmann, Rofin-Sinar Laser GmbH (Germany) \\ Symposium Cochairs \\ Peter R. Herman, University of Toronto (Canada) \\ Donald J. Harter, IMRA America, Inc. (USA) \\ Program Track Chairs \\ Henry Helvajian, The Aerospace Corporation (USA) \\ James S. Horowitz, U.S. Department of Energy (USA) \\ Conference Chairs \\ Joseph Neev, JYN Industries Inc. (USA) \\ Stefan Nolte, Friedrich-Schiller-Universität Jena (Germany) \\ Alexander Heisterkamp, Laser Zentrum Hannover e.V. (Germany) \\ Christopher B. Schaffer, Cornell University (USA)
}

Program Committee

Samer Banna, Brookhaven National Laboratory (USA)

Adela Ben-Yakar, The University of Texas, Austin (USA)

James E. Carey III, SiOnyx, Inc. (USA)

Donald J. Harter, IMRA America, Inc. (USA)

Chandrashekhar J. Joshi, University of California, Los Angeles (USA)

Daniel J. Kane, Southwest Sciences, Inc. (USA)

Eric D. Mazur, Harvard University (USA)

Nozomi Nishimura, Cornell University (USA)

Minoru Obara, Keio University (Japan)

Andreas Ostendorf, Laser Zentrum Hannover e.V. (Germany)

Levi Schächter, Technion-Israel Institute of Technology (Israel)

Brent C. Stuart, Lawrence Livermore National Laboratory (USA)

Alexander Szameit, Friedrich-Schiller-Universität Jena (Germany)

Philbert S. Tsai, University of California, San Diego (USA)

Alfred Vogel, Universität zu Lübeck (Germany)

Session Chairs

1 Ultrafast Lasers in Cell Biology

Christopher B. Schaffer, Cornell University (USA) 
$2 \quad$ Ultrafast Lasers in Imaging

Alexander Heisterkamp, Laser Zentrum Hannover e.V. (Germany)

3 Laser-Plasma-Accelerator

Samer Banna, Brookhaven National Laboratory (USA)

$4 \quad$ Laser Vacuum Accelerator

Chandrashekhar J. Joshi, University of California, Los Angeles (USA)

5 Novel Ultrafast Laser Sources

Donald J. Harter, IMRA America, Inc. (USA)

6 Novel Ultrafast Laser Sources II

Daniel J. Kane, Southwest Sciences, Inc. (USA)

7 Fundamentals of Ultrafast Laser-Material Interactions: Joint Session with Conference 6879A

J. Thomas Dickinson, Washington State University (USA)

8 Femtosecond Ablation: Joint Session with Conference 6879A

Eric Audouard, Université Jean Monnet Saint-Etienne (France)

9 Photonic Devices: Joint Session with Conference 6879A Joseph Neev, JYN Industries Inc. (USA)

10 Optical Waveguides: Joint Session with Conference 6879A Stefan Nolte, Friedrich-Schiller-Universität Jena (Germany)

11 Optical Waveguides II Joseph Neev, JYN Industries Inc. (USA)

12 Surface Structuring for Photovoltaics and Enhanced Detection James Carey III, SiOnyx, Inc. (USA)

13 Micromachining

Cord L. Arnold, Laser Zentrum Hannover e.V. (Germany) 


\title{
The Long Journey from Idea to Industrial Success
}

\author{
Holger Schlüter \\ TRUMPF Inc., Farmington Industrial Park, Farmington, CT 06032, USA
}

\begin{abstract}
It is astonishing how long it can take from the first idea to the industrial success of a laser technology product. Three laser technologies in which TRUMPF participated will be investigated from conception to realization. The first case study focuses on the diffusion cooled coaxial $\mathrm{CO}_{2}$ laser geometry with diffraction limited resonators. The second case study highlights some of the stages along the very successful route to implementation of the thin disk laser; from the conception at the IFSW ${ }^{1}$ and the ITP ${ }^{2}$, both in Stuttgart, to the successful industrial installations in automotive applications. Finally the development of high power diodes for diode pumped solid state lasers is also discussed.
\end{abstract}

Keywords: $\mathrm{CO}_{2}$ laser, diffusion cooled laser, diode pumped solid state laser, thin disk laser, high power diode laser

\section{INTRODUCTION}

The market for high power lasers in industrial material processing has grown to $\$ 2.3$ bn in 2007 according to [1]. Three types of lasers make up the bulk of these beam source revenues: $\mathrm{CO}_{2}$ lasers, excimer lasers and solid state lasers (see Figure 2). Excimer lasers are used mainly for micro machining and photolithography applications. The major market for either diffusion cooled or fast-flow multi-kW $\mathrm{CO}_{2}$ lasers is the sheet metal cutting industry. Diode pumped solid state lasers (DPSSL) are commercially available with the laser medium in the form of a fiber (often called fiber lasers) or in the form of a disk (often called thin disk lasers), a rod or a slab. Thin disk and fiber laser dominate the market place for multi-kW DPSSL.

\section{Laser Sources for Material Processing}
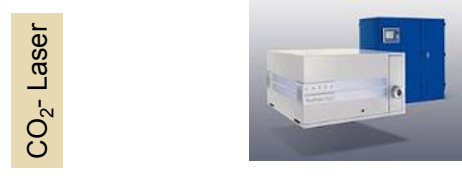

Flow Lasers

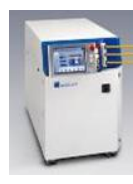

pulsed

Lamp Pumped Lasers

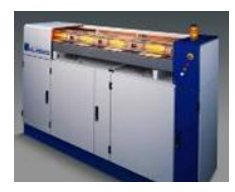

CW

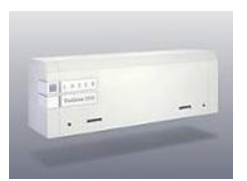

Diffusion Cooled

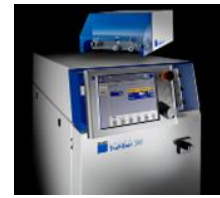

Fiber

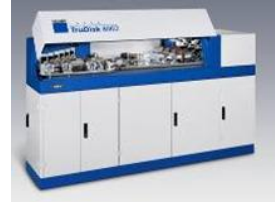

Disk

Diode Pumped Lasers

Figure 1: Laser beam sources for material processing in use today. This overview excludes excimer lasers - they are used in micromachining and photolithography applications. Diffusion cooled and fast flow $\mathrm{CO}_{2}$ lasers dominate the market for sheet metal cutting. Most solid state lasers for material processing are fiber delivered, such as thin disk and fiber lasers. This paper will focus on the diffusion cooled $\mathrm{CO}_{2}$ laser with coaxial discharge and helix resonator, the diode-pumped solid-state thin disk laser as well as the high power diode lasers used to pump solid-state lasers.

\footnotetext{
${ }^{1}$ Institut fuer Strahlwerkzeuge at the University of Stuttgart

${ }^{2}$ Institute of Technical Physics at the German Aerospace Center (DLR)
} 
Lamp pumped solid state lasers (LPSSL) remain in second place of the revenue ranking. Most likely DPSSL will replace many LPSSL because of the great advantages these systems have.

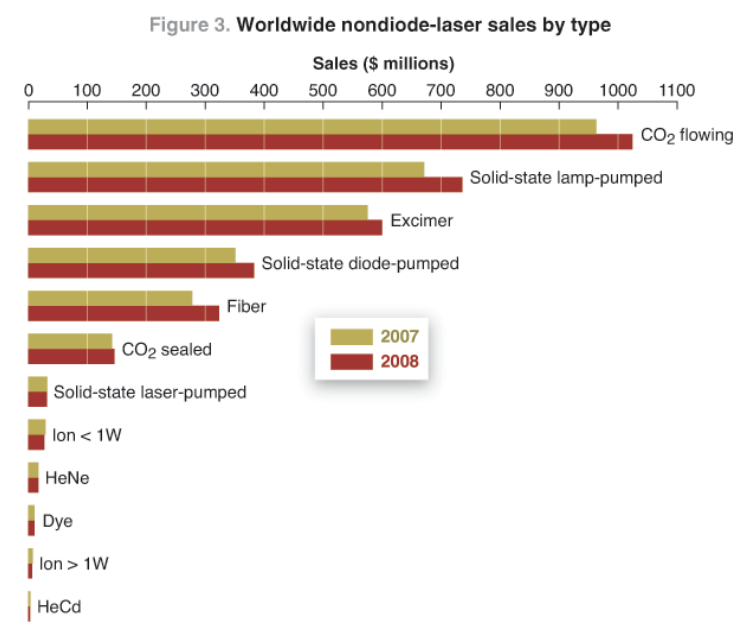

Figure 2: Worldwide nondiode-laser sales by type [1]. The product segment fast flow $\mathrm{CO}_{2}$ laser is still by far the largest segment, followed by lamp-pumped solid state lasers.

TRUMPF is the leading supplier of DPSSL as well as $\mathrm{CO}_{2}$ lasers in the industrial market place. Therefore it is interesting to investigate how long it takes a laser manufacturer like TRUMPF to transform an idea into an industrial solution that is accepted in the market. We will take three relevant examples in order to show that this process can take 10 to 15 years. The three technologies that will be investigated are diffusion cooled multi- $\mathrm{kW} \mathrm{CO}_{2}$ lasers with an annular discharge region and a high beam quality resonator for annular laser media ("The helix resonator"), the thin disk laser technology that has revolutionized multi-kW DPSSL as well as high power diode laser arrays.

\section{THE HELIX RESONATOR}

High Power $\mathrm{CO}_{2}$ lasers are successfully used in sheet metal fabrication since the early 1980's. Many of today's multi$\mathrm{kW} \mathrm{CO}$ lasers are RF excited and are operated recirculating the gas in order to convectively remove the excess heat from the discharge region (this is called flowing gas operation). Today flowing gas operation can be achieved very cost effectively and efficiently with modern turbo-blowers that utilize actively controlled magnetic bearings.

In the early 1990's a new idea - RF excited diffusion cooled laser systems emerged. In a multi-kW RF excited diffusion cooled laser system the laser discharge is operated between two water cooled large area electrodes. It can be shown that the output power $\mathrm{P}$ of such a system follows the following scaling law:

$$
P=C \cdot A / d
$$

with A: surface area of the electrodes, d: gap width between the electrodes, C: invariant scaling factor.

This shows the@-D scaling advantage of this technology as well as the great potential using reduced electrode spacing to produce high power from very compact laser devices. However, the losses generated during the optical propagation of the laser beam between the electrodes set a lower limit to the gap width. It typically varies between 2-6 mm depending on the optical design of the laser. An empirically [2] found value for the invariant scaling factor is:

$$
C=40\left[\mathrm{~kW} \cdot \mathrm{mm} / \mathrm{m}^{2}\right]
$$

Therefore at a gap width of 2-6 mm an electrode area of $500-1500 \mathrm{~cm}^{2}$ is necessary for $\mathrm{kW}$ operation. 
There are two different options to achieve such a large electrode area:

1. Build a symmetric cross-section for the laser radiation by setting the electrode width equal to the gap width and making the electrode very long. In this case gap width and electrode width cancel each other out:

$$
P / l=40[\mathrm{~W} / \mathrm{m}\rfloor
$$

2. Make the electrode width much larger than the gap width. This allows for short and compact RF excited diffusion cooled multi-kW lasers.

The first approach would require a resonator length of $25 \mathrm{~m}$ for $1 \mathrm{~kW}$ of output power. While folded resonators allow building very long resonators in a very compact manner, this is a difficult length to manage. Currently commercially available RF excited diffusion cooled lasers built using the first approach have a maximum output power of 400 Watts [3], [4]. ${ }^{3}$

For the second option, there are two possible geometries to achieve a large electrode surface area:

1. The slab geometry - two slab like electrodes define a rectangular discharge area with $A=w \cdot l$ where $w$ is the width of the electrode and $l$ the length of the electrode ${ }^{4}$.

2. The coaxial geometry - two tube like electrodes coaxially arranged define an annular discharge area with $A=\pi D \cdot l$ where $D$ is the center diameter between the inner and the outer electrodes and $l$ the length of the electrodes.

The main advantage of an RF excited multi-kW diffusion cooled $\mathrm{CO}_{2}$ laser over a fast flow laser is the absence of a gas recirculation system. However, this advantage comes at a price: The very high aspect ratio of the discharge width ( $w$ or $\pi D$ ) to gap width $\mathrm{d}$ requires novel types of laser resonators. The classical stable resonator only works in symmetric or at least nearly symmetric cross-sections. One of the major difficulties is to conceive a laser resonator that achieves nearly diffraction limited operation not only in the small direction of the aperture, but also in the wide direction of the aperture 5 . It turns out that so called unstable resonators are very suited to achieve diffraction limited operation in the wide direction of an aperture [9]. Such an unstable resonator needs to be combined with a stable resonator in the small direction of the aperture.

${ }^{3}$ At least one manufacturer offers a $2 \mathrm{~kW}$ laser without gas recirculation [5] that is built with a symmetric beam cross section. However, the laser is not RF excited; instead a DC discharge is established between an anode and a cathode inside a hermetically sealed quartz tube (very much like the discharge in a fluorescent light bulb). Such DC excited lasers are excluded from this discussion.

${ }^{4}$ It would be more correct to speak of length, width and center diameter of the discharge region - however in most cases those values are close enough to the actual electrode geometry, so for simplification the electrode geometry is referenced.

${ }^{5}$ Wide and small directions of the aperture are more exactly defined by the Fresnel number $(F)$ of the resonator, factorized into the two directions $x$ and $y$ or $r$ and $\theta$. It is defined:

$F=F_{x} \cdot F_{y}=\frac{w / 2}{\sqrt{\lambda \cdot l}} \cdot \frac{d / 2}{\sqrt{\lambda \cdot l}}$ for slab geometries and $F=F_{r} \cdot F_{\theta}=\frac{d / 2}{\sqrt{\lambda \cdot l}} \cdot \frac{\pi D / 2}{\sqrt{\lambda \cdot l}}$ for coaxial geometries, with

$\lambda$ : Laser wavelength (typ. $10.6 \mu \mathrm{m}$ ), $d$ : gap width, w: width of the discharge (slab), $D$ : center diameter annular discharge (coaxial) and $l$ : length of the discharge / electrodes.

In the $y$ resp. $r$ direction ("the small direction of the aperture") diffusion cooled lasers have a Fresnel number close to 1 , so they operate diffraction limited with a stable resonator in this direction. In the $x$ resp. $\theta$ direction ("the large direction of the aperture") multi-kW lasers have a Fresnel number on the order of 100 or more, making a different approach - for instance unstable resonators - for diffraction limited operation necessary. 


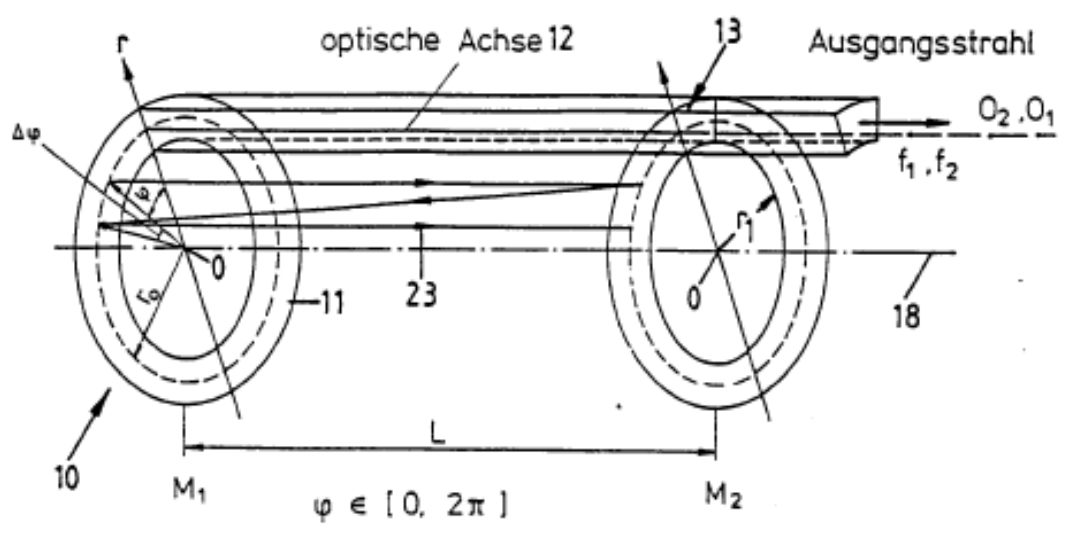

Figure 3: Drawing from DE 4123024 [10]- the original patent on the Helix-Coax resonator, filed by the Fraunhofer Gesellschaft fuer angewandte Forschung e.V., Munich. As inventors are named: Keming Du, Peter Loosen and Uwe Habich.

For the slab geometry a suitable resonator type combining an unstable with a stable resonator is the negative branch unstable hybrid resonator as patented by Tulip in 1988 [8]. Many commercial slab laser products are based on this resonator [6].

The idea for a resonator achieving a similar combination of an unstable resonator with a stable resonator for coaxial discharges was proposed at the Fraunhofer Institut Lasertechnik in Aachen, Germany (ILT) and patented in 1992 [10]. In this case the small direction (gap width) of the aperture is in the radial direction of the coaxial geometry, while the large direction of the aperture is in the azimuthal direction.

The resonator that was proposed is called helix resonator, since it makes use of a helical slope on an annular mirror in order to achieve an unstable resonator in the azimuthal direction. For more details on the helix resonator see [11].

Figure 3 shows the main figure of the first patent of the helix resonator. Inventors are Keming Du, Peter Loosen and Uwe Habich, all of the ILT in 1992. It took until 2005 for this idea to turn into a commercially successful product. This journey will be sketched in the following few paragraphs.

A first prototype of a RF excited diffusion cooled $\mathrm{CO}_{2}$ laser with coaxial discharge geometry (short: coax laser) was completed in 1993. This prototype is shown in Figure 4. The prototype consists of the discharge and mirror assembly as well as a beam shaping telescope. The beam shaping telescope reformats the beam to be rotational symmetric in space and divergence angle. The service cabinet below the laser holds the water distribution system and auxiliary equipment. The helix resonator requires sophisticated mirror manufacturing technology that was not available at that time. Therefore a simple trick was used to mimic the helix resonator: A toric annular mirror was tilted, which creates two sloped sections in reference to the plane perpendicular to the optical axis. This toric resonator is very similar to the helix resonator; however, two separate beams exit the laser.

The prototype with the toric resonator produced an output power of 1100 Watts at a discharge length of $l=1 \mathrm{~m}$, a central discharge diameter of $D=52 \mathrm{~mm}$ and a gap width of $6 \mathrm{~mm}$. It took until 1996 to develop helix mirrors and beam shaping optics for the laser, but in 1997 it could be shown that the power of the helix resonator in this laser was 1000 Watts and the beam quality of the formatted beam was nearly diffraction limited. This is equivalent to a scaling constant of $40 \mathrm{~kW} \mathrm{~mm} / \mathrm{m}^{2}$. TRUMPF was funding these efforts at ILT with the intention to keep in touch with diffusion cooled technology. In 1996 TRUMPF decided to use this technology in order to quickly develop and build a laser for a special customer. 


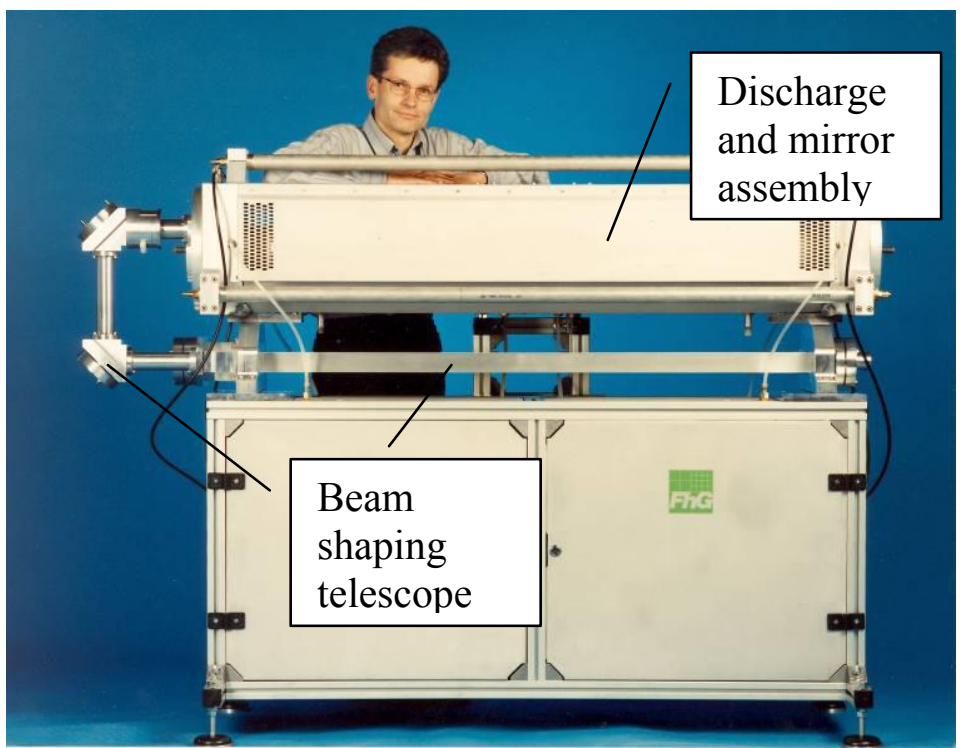

Figure 4: The first RF excited coaxial diffusion cooled laser with Helix resonator. This device was built at the Fraunhofer Insitut Lasertechnik in 1993.

Figure 5 shows the first generation of heart lasers sold by PLC of Franklin, MA and which cardiac surgeons use to perform $\mathrm{CO}_{2}$ transmyocardial revascularization (TMR) to alleviate symptoms of severe angina. Until $1996 \mathrm{TRUMPF}$ sold about 70 fast axial flow $\mathrm{CO}_{2}$ lasers to PLC for use in their product. However, the axial blower had some severe downsides for this particular application, including size, noise and start-up time.

Therefore PLC asked TRUMPF to develop a diffusion cooled version and TRUMPF saw a chance to quickly provide PLC with a solution based on the "almost production ready" prototype of the coax laser.

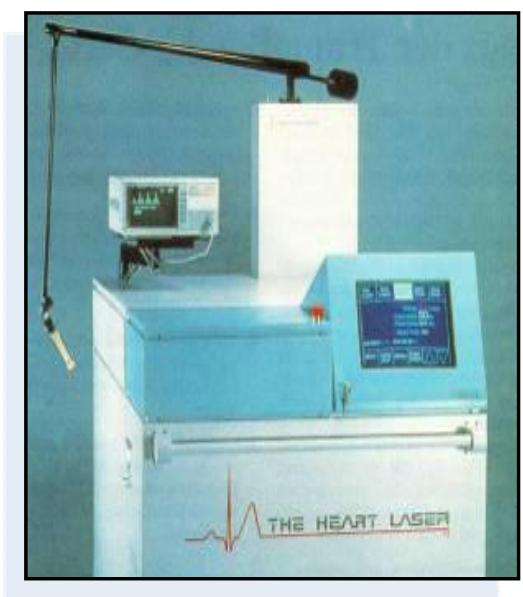

Figure 5: The Heart Laser - this laser system was sold by PLC, MA and contained a fast axial flow laser from TRUMPF.

TRUMPF was asked to develop a diffusion cooled $\mathrm{CO}_{2}$ laser to replace the fast axial flow laser in 1996.

This would also allow TRUMPF to develop a diffusion cooled laser product for use in other applications and complete its $\mathrm{CO}_{2}$ laser product line. In addition it was planned to use this product to establish a high power development group at the TRUMPF subsidiary in Farmington, CT. TRUMPF Inc. in Farmington, CT was already building and assembling fast-axial flow lasers for the North American market, including all lasers for PLC. However these lasers were built according to drawings provided by TRUMPF, Germany. The new product provided the opportunity to train a product development team in Germany and then transfer a core team together with laser knowledge to TRUMPF Inc. in order to establish full laser R\&D capability and complete the already existing production, sales, service and application departments. 
Figure 6 shows the first coax laser design built by the newly established product development group at TRUMPF in Ditzingen, Germany. It was based on the geometry of the first coax laser at the ILT. However, the outer electrode was chosen to be grounded, while the inner electrode was connected to the RF power supply. This allowed the outer electrode to provide the RF shielding as well as the resonator support structure. This in turn allowed a more compact setup then the first prototype at the ILT. The laser was first assembled in 1997 and provided with $1=1000 \mathrm{~mm}, \mathrm{D}=55$ $\mathrm{mm}$ and $\mathrm{d}=6 \mathrm{~mm}$ also 1000 Watt. Again the scaling factor was close to the maximum value at $40 \mathrm{~kW} \mathrm{~mm} / \mathrm{m}^{2}$.

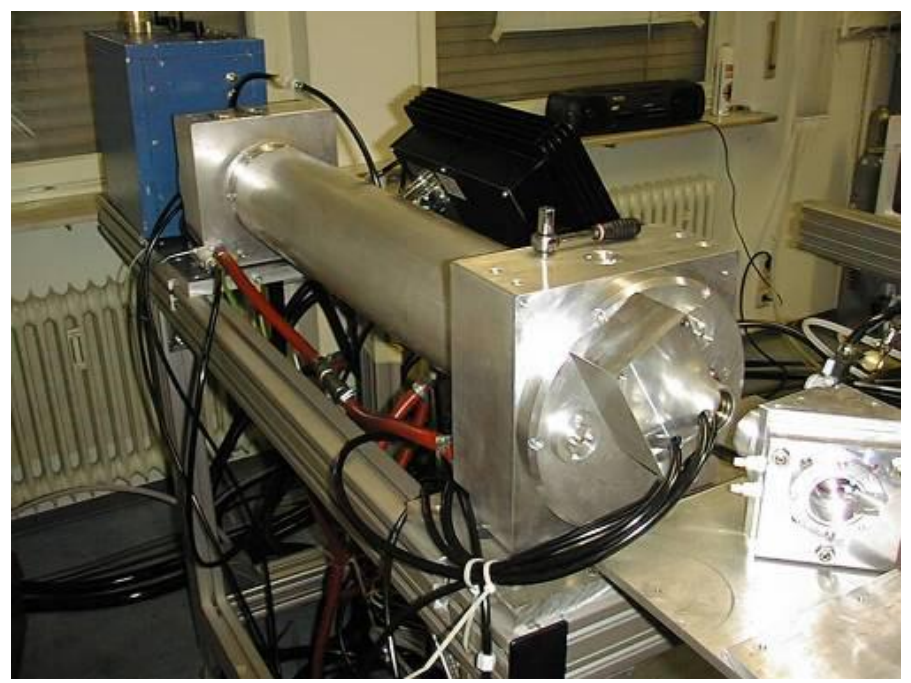

Figure 6: First Coax laser at TRUMPF. This system had a similar geometry as the system at the ILT. However, by combining the resonator support structure and the RF shielding in the outer electrode it became possible to build the system more compact than the first prototype. This laser also had diffraction limited laser output at a power level of about 1000 Watt.

After detailed analysis of the laser it became clear that the laser output power was very unstable, the wavelength of the laser would unpredictably change and the mirrors were very sensitive to misalignment. The team was able to link this behavior to the helix resonator and developed a modified version, the so called helix-axicon resonator. A patent was filed [12] and a new laser based on the helix-axicon resonator was designed and built.

Figure 7 compares the helix resonator and the helix-axicon resonator geometries. The helix resonator consists of a toroidal rear mirror and an annular helix mirror with a helical slope in the azimuthal direction. This slope forces the beam on an azimuthal path and any photon along this path will eventually leave the resonator through an aperture in the form of an annular section. This resonator setup is very sensitive to misalignment and not very stable. A new design replaced the toroidal rear mirror with an axicon. The axicon has a retro-reflector effect - which means that an incident beam is reflected back into the exact same direction as the incident beam regardless of the tilt of the axicon (in first approximation). This effect has tremendously improved resonator alignment sensitivity and power stability. The increased resonator length (doubled by the axicon) removed the wavelength fluctuations and the axicon also stabilized the state of polarization.

The first prototype based on the helix-axicon resonator was finished in 1998 and the geometry was adjusted to $\mathrm{D}=77.5$ $\mathrm{mm}$ (the rest stayed the same: $1=1000 \mathrm{~mm}, \mathrm{~d}=6 \mathrm{~mm}$ ). Provided the scaling constant would remain stable at $40 \mathrm{~kW} \mathrm{~mm} / \mathrm{m}^{2}$ this should have allowed operation at 1500 Watt. At that time it was already clear that TRUMPF intended to use this technology for thin gauge sheet metal cutting and 1500 Watt provided (at that time) an interesting market niche in thin sheet metal cutting. 


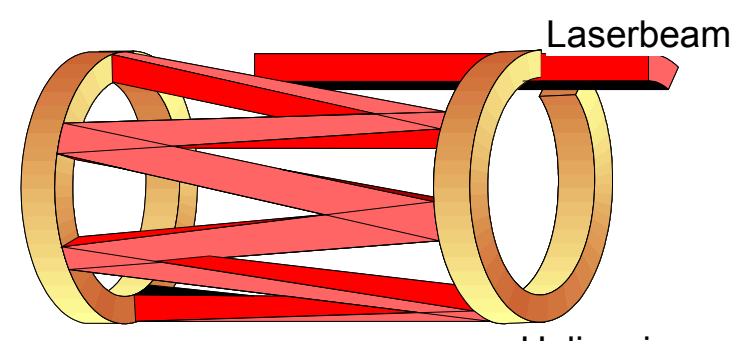

Helix mirror

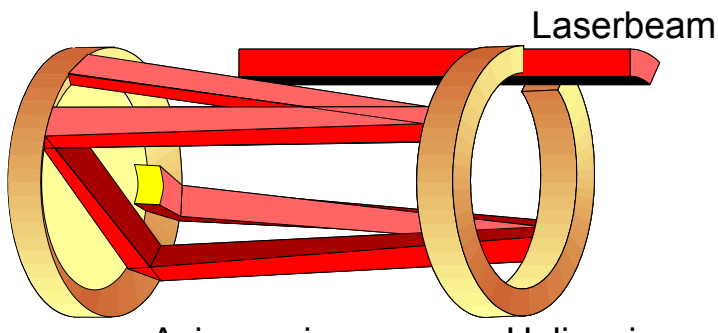

Axicon mirror
Helix mirror

Figure 7: The helix resonator (left) consists of a toroidal rear mirror and an annular helix mirror with a helical slope in the azimuthal direction. This slope forces the beam on an azimuthal path and any photon along this path will eventually leave the resonator through an aperture in the form of an annular section. This resonator setup is very sensitive to misalignment and not very stable. A new design replaced the toroidal rear mirror with an axicon (right).

The laser worked very stable, just as was anticipated. The axicon improved the alignment stability by at least a factor of 20 - measured by the misalignment angle of a resonator mirror that would lead to significant power loss. While this angle was at $50 \mu \mathrm{rad}$ for the helix resonator it increased to $1000 \mu \mathrm{rad}$ for the helix-axicon resonator.

However, the output power of the laser remained at 1000 Watts. Many issues and problems were investigated and fixed over the next 16 months, but the maximum laser power that could be achieved remained at 1000 Watts. Several prototypes were built, none of them with more then 1000 Watts of output power.

After solving many issues, including gas chemistry, mirror deformation, RF distribution and others, the power meter one day unexpectedly showed 1200 Watts. This was so unexpected that the accuracy of the power meter was questioned. However, the next day the power meter showed 1500 Watts and within one week the same laser that was stuck at 1000 Watts for more than 16 months now broke the 2000 Watts barrier. At 2000 Watts the scaling factor for this geometry is $50 \mathrm{~kW} \mathrm{~mm} / \mathrm{m}^{2}$.

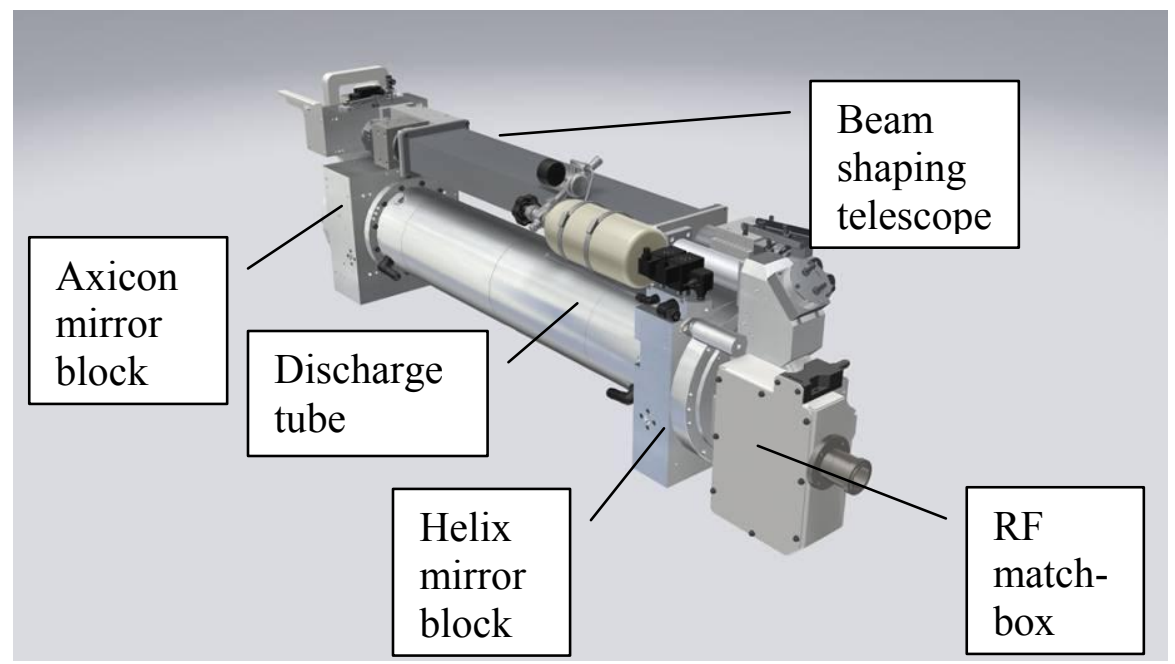

Figure 8: 3 D schematics of a TruCoax resonator with the discharge tube, the mirror blocks attached to the discharge tube, the beam shaping telescope, the RF matchbox in the front, the gas bottle used to refill the gas, lasting at least a year of operation.

In 2000 a core team consisting of 4 members of the German coax development team moved together with the project to the United States and established the high power laser development department at TRUMPF Inc. in Farmington, CT. In the summer of 2000 the first coax laser was operational at the newly built laboratory in the US. Many new employees needed to be hired and trained, vendors needed to be qualified and production processes needed to be established.

A major technical difficulty was uncovered and fixed - it had to do with the locally varying state of polarization due to the annular shape of the resonator mirrors. With the first design of the beam shaping telescope it was not possible to convert this state of polarization into the required circular state of polarization. However a solution was found and 
implemented. This additional project cost the team about 1 year in development time; the move to the United States may have contributed to an additional year.

Average Power after Telescope

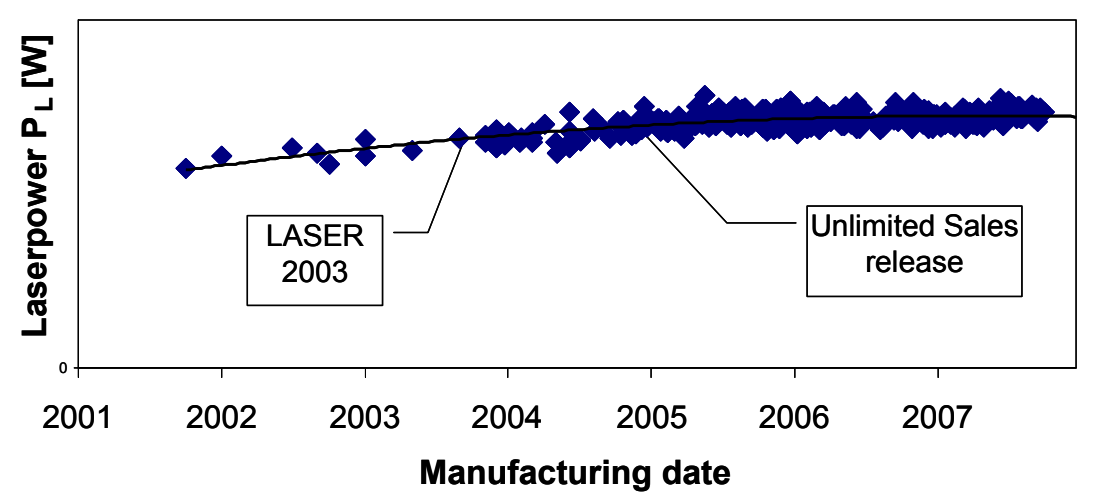

Figure 9: In this graph the normalized laser output power is plotted against the laser manufacturing date. Until 2003 about 10 lasers were built and tested internally. After presenting the laser to the public in 2003 about 50 units were delivered to chosen customers for extensive field tests until the product was released for unlimited world wide sales in 2005. At that point it had taken 13 years from idea to industrial product.

From 2001 to 2003 the product design was completed, housing, water distribution, safety mechanisms were developed and designed. Controls and software were developed and adapted. Operator manuals needed to be written, reliability and other tests needed to be performed. Several improvements were implemented. Figure 9 shows the normalized laser output power against the laser manufacturing date. Until 200310 lasers were built and internally tested. After presentation to the public on the Laser 2003 in Munich another 50 units were built and tested at chosen customers. In 2005 the product was released for unlimited world wide sales. In the same year the $100^{\text {th }}$ laser was shipped out of Farmington, CT. Since then the TruCoax family has created nearly 40 jobs in Connecticut and enabled more than $\$ 100$ million revenue in laser and related systems business. Without the patience and endurance of the entire team and management of the TRUMPF group this success would not have been possible. Currently a 3200 Watt version of the Coax laser is in preparation and has been presented to the public.

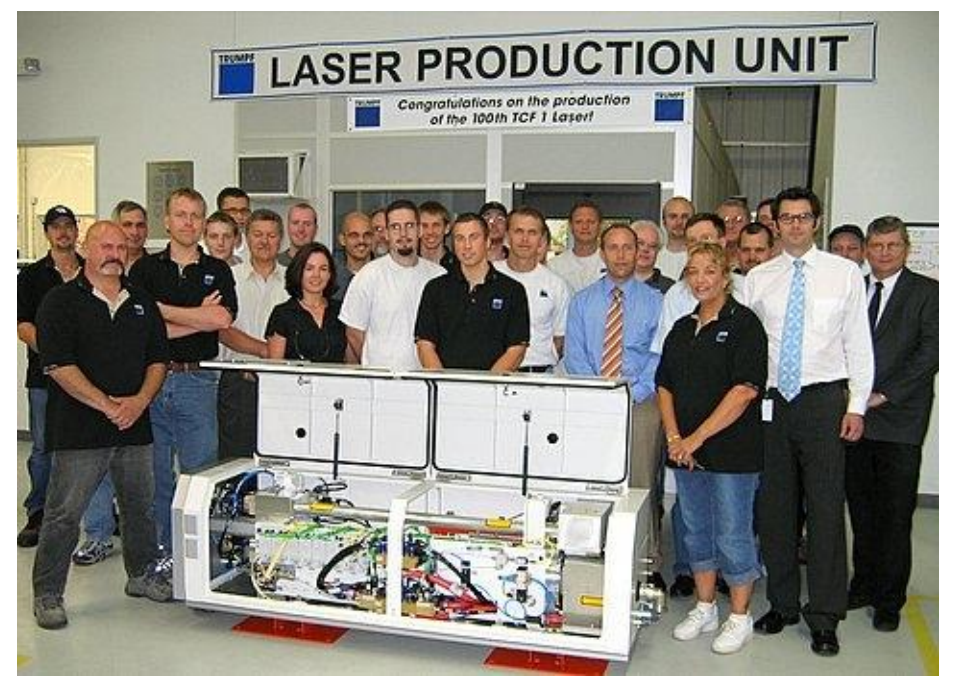

Figure 10: Completion of the 100th Coax laser in 2005. Until this point it had taken 13 years from the patent to the industrial success. Since then the Coax laser has generated more then 40 jobs in Connecticut and generated more then $\$ 100$ million in laser and related system revenue. Without the patience and endurance of the entire team and management of TRUMPF this great success would not have been possible. 


\section{THE THIN DISK LASER}

High power solid state lasers - high power loosely defined as an average output power above $1 \mathrm{~kW}$ - dominate laser welding. TRUMPF alone has more than 8000 units installed worldwide. Only recently have multi-kW diode pumped solid state lasers outnumbered the sales of multi-kW lamp pumped Nd:YAG lasers in industry. Multi-kW solid state lasers are used in automotive production, ship building, construction and other market sectors. The major advantage of high power solid state lasers over $\mathrm{CO}_{2}$ lasers is the ability to transport the power using a fiber optical cable. This enables the remote installation of the laser and the articulation of a small welding head for instance at the end effector of a robot.

One of the major drawbacks of lamp pumped solid state lasers in the multi-kW class has been the lower beam quality and wall-plug efficiency than $\mathrm{CO}_{2}$ lasers of comparable power.

\section{Patent Number: $\quad 5,553,088$}

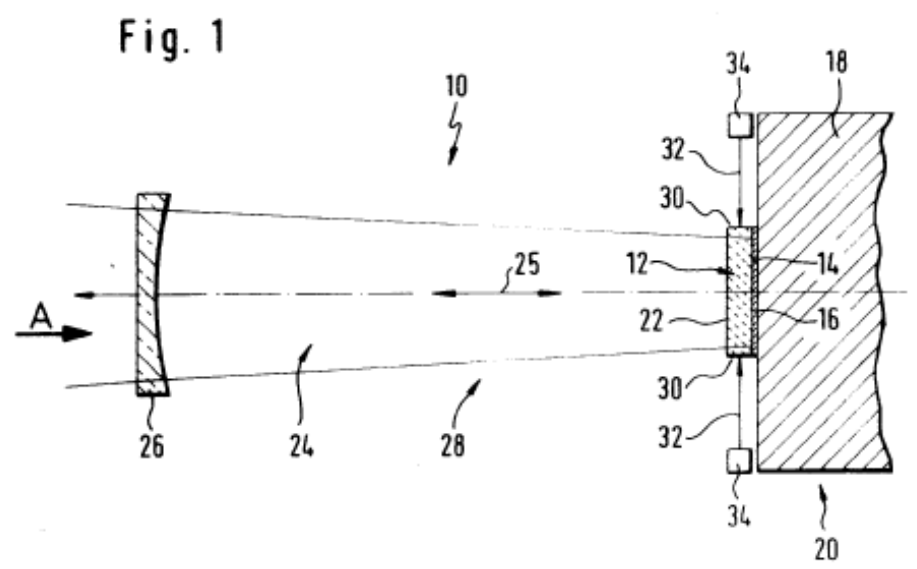

Figure 11: Figure 1 of the first thin disk laser patent [13] assigned to IFSW ${ }^{6}$ and the ITP ${ }^{7}$, both Stuttgart, Germany. Inventors are Adolf Giesen, Uwe Brauch, Klaus Wittig and Andreas Voss. The thin disk laser medium (12) is pumped by a diode laser pump source (34) and an external resonator extracts the power from the thin disk laser crystal. In today's thin disk lasers the diode laser pump beam is incident under a shallow angle to the optical axis and passes through the disk up to 32 times.

The reason for the low beam quality of the lamp pumped Nd:YAG lasers can be found in the thermo-optical properties of the setup. The pump light of the lamp emits a spectrum of which only a small portion is actually transferred into the upper laser level in the rod shaped laser crystal. This leads to the very low optical-optical efficiency of a lamp pumped $\mathrm{Nd}: Y A G$ laser and the very low wall plug efficiency of $2-4 \%$.

The lamp emits on many different wavelengths. Pump radiation with higher photon energy than required for pumping the upper laser level is absorbed by the laser crystal. This causes an excessive heat flux in the laser crystal. The laser crystal is typically cooled using a fluid flow tube surrounding the Nd:YAG rod. Therefore the heat can only be removed on the cylindrical surface of the rod, while the power is absorbed in the rod volume. This yields a strong thermal gradient in the rod, which in turn creates a non-spherical variation of the index of refraction in the crystal perpendicular to the optical axis. In addition birefringence is induced in the crystal. All these thermo-optical effects are power dependent and can hardly be compensated. Therefore a compromise has to be found for a dynamically stable resonator that can be operated over a large range of pump powers. Such a compromise does not allow for a high beam quality resonator.

By introducing a diode pumped thin disk solid state laser medium all of these drawbacks can theoretically be eliminated. The diode laser emission can be perfectly matched to the absorption spectrum lines of the crystal. Diode lasers

\footnotetext{
${ }^{6}$ Institut fuer Strahlwerkzeuge at the University Stuttgart

${ }^{7}$ Institute of Technical Physics at the German Aerospace Center (DLR)
} 
themselves have high electro-optical efficiency (typically above 60\%). Together with the outstanding optical-optical efficiency of the thin disk laser (also greater $60 \%$ over a large range of operating conditions) and the low coupling losses (due to the large aperture of the thin disk) a very high wall plug efficiency of up to $27 \%$ (including auxiliary components) can be achieved.

In addition, the thin disk is cooled from the back side, so that the thermal gradient in first approximation is along the optical axis and therefore hardly induces any optical aberration. This enables high power operation with very good beam quality. Today thin disk lasers achieve similar values for output power and beam quality as $\mathrm{CO}_{2}$ lasers of comparable output power and will enable new markets that require the ability to deliver the beam through an optical fiber assembly.

The first disk laser patent was awarded in 1993 to the IFSW and the ITP, both Stuttgart, Germany. Inventors are Adolf Giesen, Uwe Brauch, Klaus Wittig and Andreas Voss [13]. A figure from the original patent is shown in Figure 11.

The first results of a thin disk laser were presented in 1994 [14], the pump beam was delivered using single emitters and transmissive imaging optics as shown in Figure 12. The output power reported was 2 Watts.
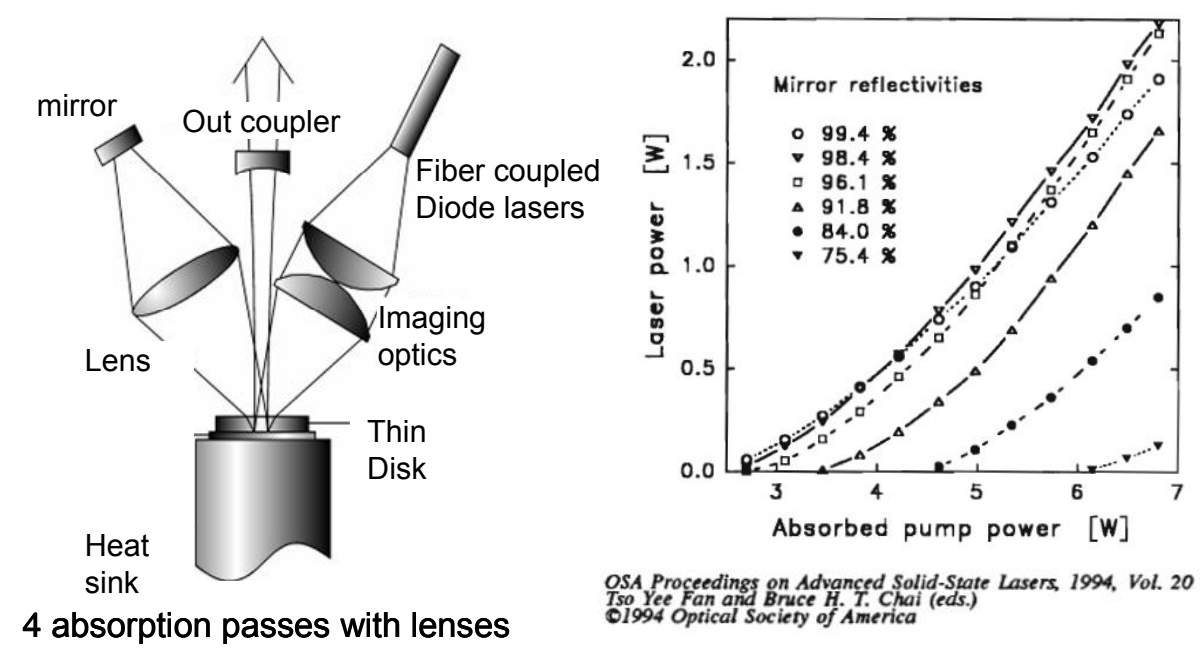

Figure 12: First reported results of the thin disk laser concept in 1994 [14]. The thin disk laser medium is pumped using fiber coupled single emitters and an output power of 2 Watts is reported.

After this first report, already in 1995 mode locked sub-ps operation was reported [15]. In the same year 10 Watts of average output power were reported [16]. 100 Watts were achieved in 1998 [17] and 1000 Watts (from 4 disks) resp. 647 Watts from one disk in 2000 [18].

Early on the IFSW and the ITP licensed the technology to interested industrial laser manufacturers and have awarded 20 such licenses as of now [19]. The referenced publication is also a very good summary of the current thin disk laser technology and its scalability in cw and ultra short pulsed operation.

TRUMPF started to work with the IFSW in 1996 and has since developed a high power platform that enables a large variety of products. Already at Laser 1999 in Munich the technology was presented to the public. The TRUMPF thin disk lasers are based on a multi-pass pump cavity that is shown in Figure 13. The collimated pump beam with a center wavelength of $940 \mathrm{~nm}$ enters the pump cavity through an aperture and is focused onto the thin disk with a large parabolic mirror.

The focused pump beam passes through the thin disk (100-200 $\mu \mathrm{m}$ thick and approx. $15 \mathrm{~mm}$ diameter) and is reflected by a thin film HR reflector on the back side of the disk. It passes through the disk again towards the parabolic mirror. Because of the optical setup, in this case the parabolic mirror collimates the pump beam again - it travels to a prism pair on the opposite side of the pump cavity. The prism pair displaces the pump beam and retro-reflects the beam to the parabolic mirror. Here the process starts again and continues until the pump beam has passed the thin disk 10 (in some design 8) times. Now the pump beam is reflected by a plane reflector (pump reflector) at a position opposing the parabolic mirror and the entire beam path is traced backwards for another 10 passes. Altogether the pump beam passes through the thin disk 20 times. Up to 32 passes of the pump radiation through the disk have been reported. 


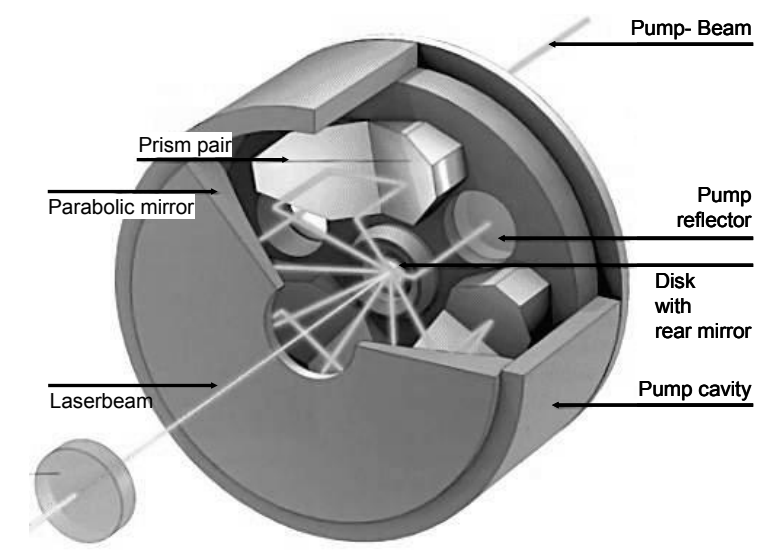

Figure 13: Pump cavity of a thin disk laser. Detailed description in the text.

The backside of the thin disk is also coated with an HR coating for the thin disk laser wavelength of $1030 \mathrm{~nm}$. Together with the large aperture in the center of the parabolic mirror this allows to integrate the thin disk pump cavity into resonators with up to 4 thin disk pump cavities in series (TRUMFP design). Further scaling is possible by adding more disks to the resonator.

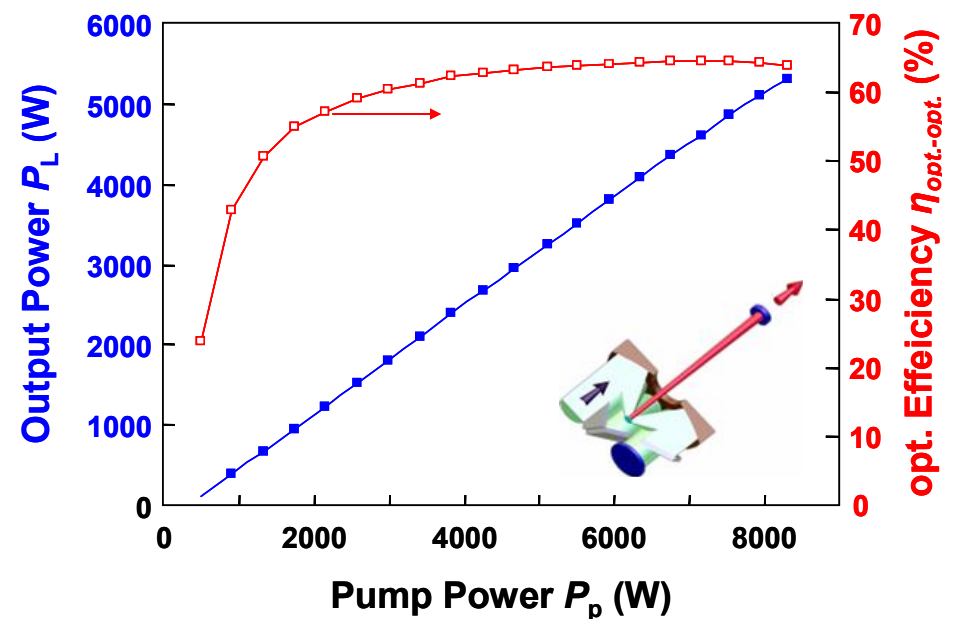

Figure 14: Output power characteristic of a single disk. An optical-optical efficiency $>60 \%$ over a wide range of operating conditions is achieved. The industrial solutions are operated at maximum of $2.5 \mathrm{~kW}$ per disk. An industrial four disk system achieves $10 \mathrm{~kW}$ of output power.

One of the major advantages of the thin disk laser is its true power scalability. That means, that power and brightness truly scale when the characteristic dimension (in this case the diameter of the disk) is increased. The reason for this scaling property is that all critical thermal and optical densities remain the same if the power is scaled with the square root of the thin disk diameter. The concept of true power scalability is well explained in [20].

At TRUMPF, the current high power series is built on a pump cavity rated at $2 \mathrm{~kW}$ output power guaranteed at the work piece. The same module can be operated at $5 \mathrm{~kW}$ without inducing any catastrophic damage. The power characteristic of a thin disk with up to $5 \mathrm{~kW}$ output power is shown in Figure 14.

Figure 15 shows a commercially available $8 \mathrm{~kW}$ thin disk laser with four pump cavities in series. This system has a guaranteed output power of $8 \mathrm{~kW}$ at a beam quality of $8 \mathrm{~mm} \cdot \operatorname{mrad}$. It is used in many different automotive and thick plate welding applications. 


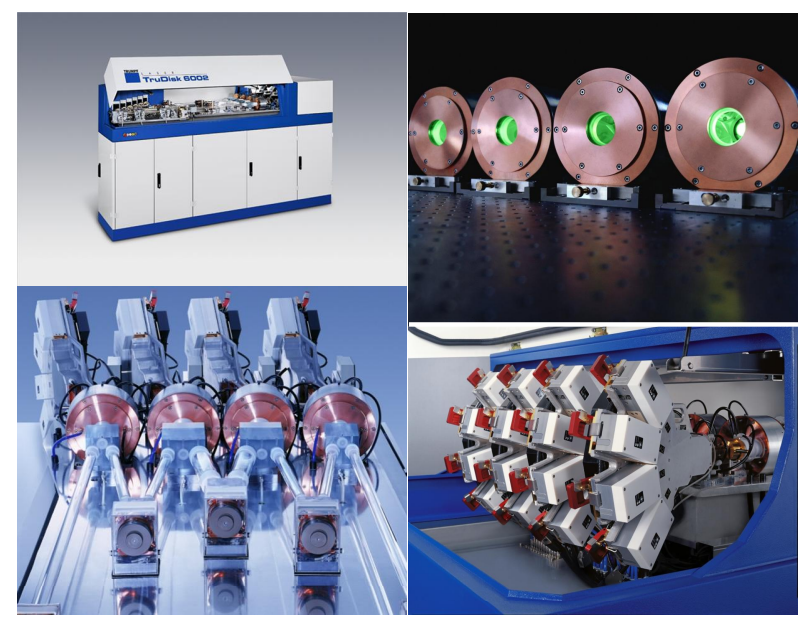

Figure 15: Commercially available $8 \mathrm{~kW}$ thin disk laser. Upper left: The entire laser system including chiller, beam switch and controls enclosed in a compact enclosure. Upper right: the four disks inside the pump cavities - the photoluminescence of the disks is visible. Lower left: The resonator setup with four thin disk modules in series, enabling a guaranteed output power of $8 \mathrm{~kW}$ at a beam quality of $8 \mathrm{~mm} \cdot \operatorname{mrad}$. Lower right: Each pump cavity is pumped with 4 individual stacks of high power diode laser arrays that can be exchanged by a trained operator within a few minutes.

Again it has taken at least 10 years from the patent to the industrial success of the thin disk laser. Exemplary this progress is summarized in Figure 16, where the power per disk (laboratory results) is compared to the industrial available laser power. The industrial success of the thin disk laser was enabled not only by the idea developed at the IFSW and the ITP, but also by the availability of reliable and cost effective high power diode laser arrays. This technology is based on many different ideas and developments and the next section will highlight how a particular fundamental idea - the broadened waveguide technology - has played a major role in the industrial success of high power diode laser arrays.

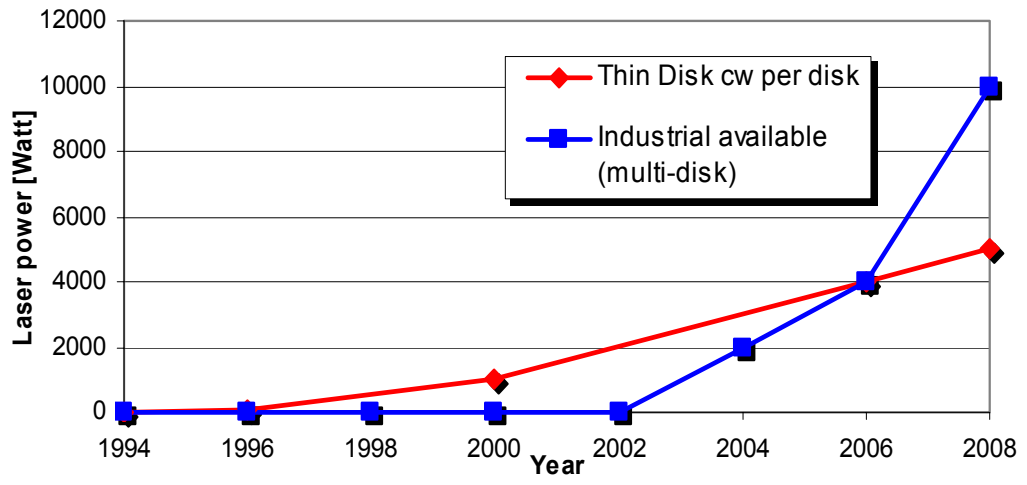

Figure 16: Thin disk cw power per disk (laboratory results) and power level of industrially available (multi-disk) thin disk laser systems vs. time. Again it took at least a decade from the patent in 1994 to industrial success. 


\section{BROADENED WAVEGUIDE TECHNOLOGY AND HIGH POWER DIODE LASERS}

In 1991 Dmitri Z. Garbuzov proposed a novel vertical structure for high power diode lasers that utilizes a broadened waveguide. In this structure the fundamental mode has very little overlap with the doped cladding layers, which drastically reduces the losses of such a system. This enabled very long devices and therefore very low thermal resistance values. Garbuzov was working at the A.F. Ioffe Physical Technical Insitute in Leningrad at the time and developed his idea. 1991 Garbuzov presented results that increased the world record for high power diode laser emitters 5 fold from 1 Watt for a $100 \mu \mathrm{m}$ stripe width to 5 Watts [21]. More than 15 years after the first results were presented, the combination of high efficiency and low thermal resistance has enabled record powers of nearly 1000 Watts from a single $1 \mathrm{~cm}$ wide high power diode laser array [30].
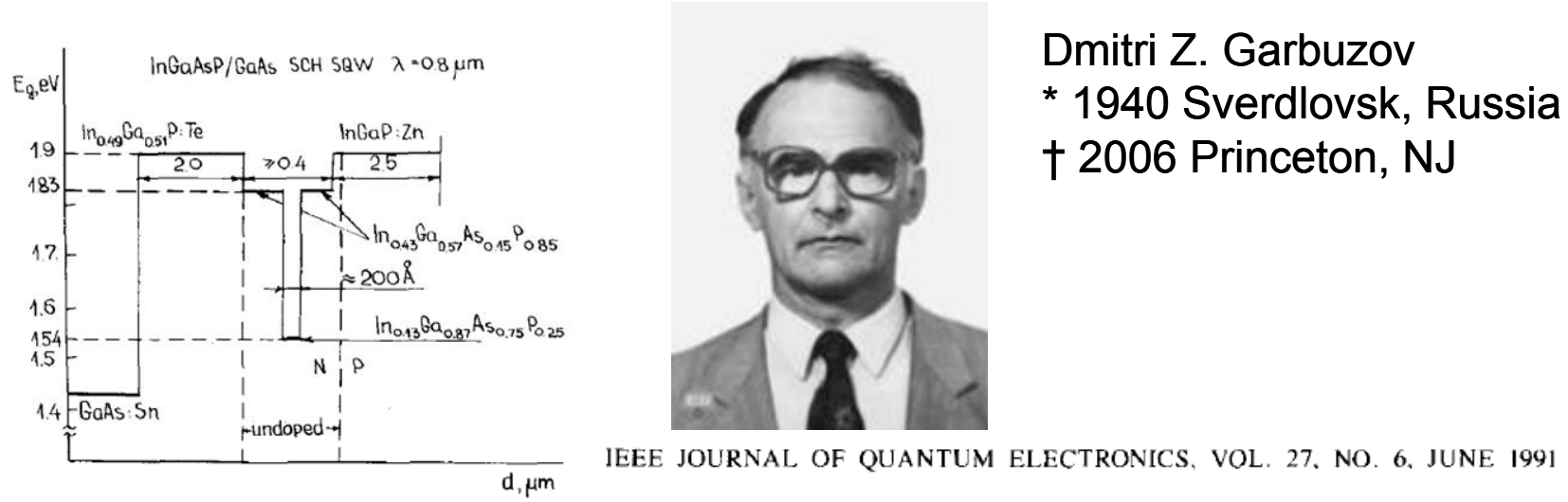

Figure 17: In 1991 Garbuzov presents the results of a novel high power diode laser vertical structure that would have a broad area waveguide and therefore very little overlap with the doped cladding layers. Already in 1991 his team can show 5 Watt output power from a $100 \mu \mathrm{m}$ stripe [21].

High power diode pump sources, used for high power solid state laser pumping are typically made up of an ensemble of emitters with single mode output in the vertical direction and multimode operation in the horizontal direction. The horizontal aperture - also called stripe width - for a high power diode laser is typically between 50 and $200 \mu \mathrm{m}$ wide. One parameter (of many) that shows the capability of a certain high power structure is the output power per $100 \mu \mathrm{m}$ stripe width. This measure will be used in the section to compare results. Since a large number of such emitters are needed to pump a multi-kW solid state laser it is convenient to look at the output power of an integrated array of such single stripes. It is common to compare the output of a $1 \mathrm{~cm}$ wide array of 45-50 such emitters, each with a stripe width of $100 \mu \mathrm{m}$. A direct comparison between the $100 \mu \mathrm{m}$ stripe results and the $1 \mathrm{~cm}$ array is not possible, since the array cannot reach the same output power due to three dimension heat conduction effects between the neighboring emitters.

The broadened waveguide technology has had a long lasting impact on high power diode lasers as well as on diode pumped solid state lasers. In 1994 Garbuzov joins the David Sarnoff Research Center and Princeton University in Princeton, NJ.

Within 5 years a new semiconductor laser material structure with greater than 10 Watts of output power from a $100 \mu \mathrm{m}$ wide emitter was realized [23]. For the first time, J. H. Abeles, J. C. Connolly and D. Z. Garbuzov demonstrated optical and electronic processes could be optimized individually [22]. In the year 2000 Princeton Lightwave Inc. (PLI) is spunoff from the David Sarnoff Research Center with 5 founders from Sarnoff, including Garbuzov and Connolly to commercialize the broadened waveguide technology for telecommunications applications. Within 2 years PLI reports [23] single-mode power levels $>1$ Watt from InGaAsP / InP. This had major impact on the telecommunication technology and market. About 2 years after the breakdown of the telecommunications market TRUMPF acquired the broadened waveguide technology and the semiconductor growth and processing facility from PLI.

Figure 18 shows the progression of laboratory and commercially available output powers from $1 \mathrm{~cm}$ wide high power diode laser arrays over time. Today these devices are commercially available with 100 Watt output power [24] and almost 1000 Watts qcw have been shown in the laboratory [30]. Two distinct time periods of commercial success can be identified. Around 1998 the availability of high power diode laser arrays with 20-40 Watts of output power enabled many different diode pumped solid state lasers with powers of a few Watts, but typically pulsed and frequency 
converted. These lasers were very successful in micro-processing. Around the year 2001 the market for marking laser systems also changed over entirely from lamp pumped to diode pumped solid state lasers, driven by the availability of fiber coupled 20 watt (later $40 \mathrm{Watt}$ ) arrays.

A few years later, around 2005, industrial availability of high power diode lasers with more than 5 Watt per $100 \mu \mathrm{m}$ stripe and 80 Watts from a $1 \mathrm{~cm}$ array enabled cost effective multi-kW operation of diode pumped solid state lasers. Currently many efforts are geared towards driving the output power per device even higher, therefore further reducing the investment cost for high power thin disk and fiber lasers.

$1 \mathrm{~cm}$ Laser Diode Array Power vs. Time

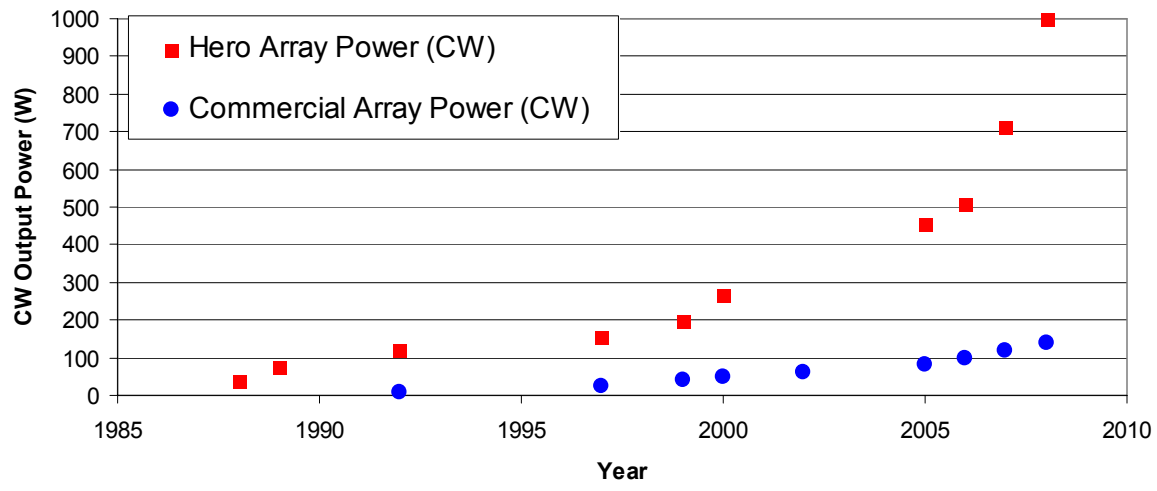

Figure 18: Laboratory and commercially available output powers from $1 \mathrm{~cm}$ wide high power diode laser arrays over time. Today these devices are commercially available with 100 Watt output power and almost 1000 Watts have been shown in the laboratory. The broadened waveguide technology was one of the fundamental enabling technologies for this success. Results from [26], [27], [28], [29], [30]

Figure 19 shows the P-I characteristic of such a next generation device, manufactured at TRUMPF Photonics. Mounted on a micro-channel cooler the device is capable of deploying 200 Watts of output power at a junction temperature $T_{j}$ of $60^{\circ} \mathrm{C}$. While record power levels of nearly 1000 Watts were reported, it is important to look at the output power at a low junction temperature, as the degradation of the laser material is exponentially dependent on the junction temperature. A junction temperature $T_{j}$ of $60^{\circ} \mathrm{C}$ will ensure degradation rates that enable tens of thousands of hours of operation. The two curves represent different fill factors (33\% and 50\%) - the results are discussed in [31].

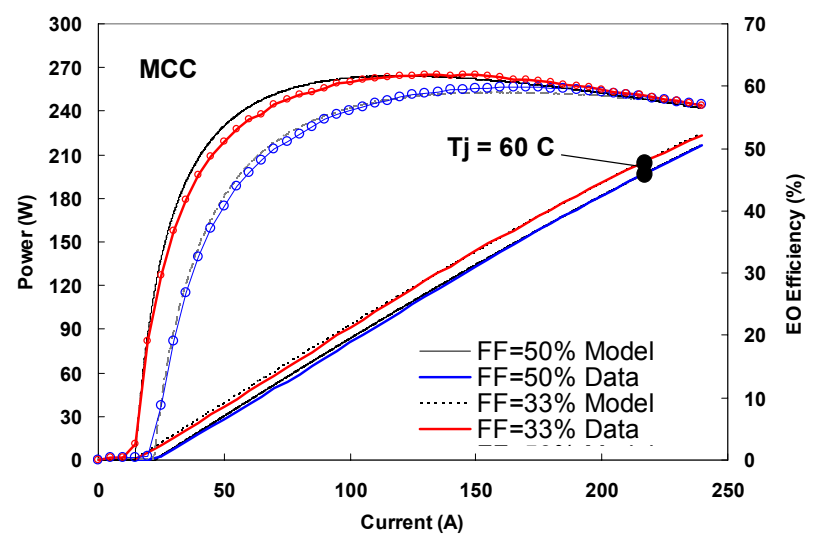

Figure 19: P-I characteristic of a modern $1 \mathrm{~cm}$ wide high power diode laser array, manufactured at TRUMPF Photonics. Mounted on a micro-channel cooler the device is capable of deploying 200 Watts of output power at a junction temperature $\mathrm{T}_{\mathrm{j}}$ of $60^{\circ} \mathrm{C}$. While record power levels of nearly 1000 Watts were reported, it is important to look at the output power at low junction temperature, as the degradation of the laser material depends exponentially on it. [31] 
Today the broadened waveguide technology has become an enabling part of industrial diode pumped solid state lasers. More than a decade passed from the formulation of the first idea in 1991 to the deployment in diode pumped marking lasers in 2001 and until 2005 for the deployment in high power diode pumped solid state lasers.

\section{CONCLUSION}

Diffusion cooled $\mathrm{CO}_{2}$ lasers with coaxial discharge, diode pumped thin disk lasers, high power diode laser arrays - in all cases it took 10-15 years for a novel idea to become an industrial success. While these are only three case studies, it seems conceivable that this long time scale for development and commercialization demonstrates a fundamental timescale in the high-technology sector. It is particularly interesting how little the time frame is impacted by the individual approaches and boundary conditions - in one case a development department was created and moved from Germany to the United States, in the other case the technology remained the entire time within Germany, in the third case a scientist and his team came from Russia, joined a US research center, spun-off a start-up company and eventually got acquired by TRUMPF. None of these aspects seem to matter. It seems to take time for a technology to be transferred into industry, regardless of the individual approach.

If the time scale of 10 years or more for commercialization is correct, it is important for future developments to try to anticipate what alternative, existing technologies might achieve through their improvement in those 10 years and develop a technology that is still disruptive 10 years from now.

\section{ACKNOWLEDGEMENTS}

The author wishes to thank the following individuals for their generous support in putting this short history together:

Joseph Abeles, Sarnoff Corp., Princeton, NJ

John Connolly, Innovative Photonic Solutions, Princeton, NJ

Andreas Voss, Institut fuer Strahlwerkzeuge - IFSW, Stuttgart, Germany

Christof Hertzler, Christian Schmitz, Christine Benz, Jochen Deile, Greg Charache and John Hostetler, all from TRUMPF in various locations and countries.

The author wishes to thank the original inventors and the hundreds of people that made these ideas an industrial success:

Joseph Abeles, Uwe Brauch, John Connolly, Keming Du, Dmitri Garbuzov, Adolf Giesen, Uwe Habich, Peter Loosen, Andreas Voss, Klaus Wittig, the staff at the ILT in Aachen, at Princeton Lightwave, at the Ioffe Institute, at the Sarnoff Corporation, at the IFSW, at TRUMPF Photonics, TRUMPF Inc., TRUMPF in Germany and many, many more

\section{REFERENCES}

[1] Kincade, K., Anderson, S., G., "LASER MARKETPLACE 2008: Innovation opens the door for next wave of success", Laser Focus World, 44 (2), 74-95 (2008)

[2] Vitruk, P., P., Baker, H., J., Hall, D., R., "Similarity and scaling in diffusion-cooled RF-excited carbon dioxide lasers", IEEE J. of Quantum Electronics, 30 (7), 1623-1634 (1994)

[3] Product brochure, Firestar f400, Synrad, www.synrad.com

[4] Product brochure, Diamond E-400, Coherent, www.coherent.com

[5] Product brochure, SM 2000 E, FeHa Laser, www.feha-laser.de

[6] Product brochure, rofin DC series, Rofin Sinar, www.rofin.com

[7] Product brochure, TruCoax, TRUMPF, www.trumpf-laser.com

[8] Tulip, J., "Carbon dioxide slab laser", United States Patent 4,719,639 (1988)

[9] Siegman, A., E., [Lasers], University Science Books, $903 \mathrm{ff}$ (1986)

[10] Du, K., Loosen, P., Habich, U., "Laser resonator", German patent DE 4123024 (1992)

[11] Ehrlichmann, D., Habich, U., Plum, H.-D., Loosen, P., Herziger, G., "Azimuthally unstable resonators for highpower $\mathrm{CO}_{2}$ lasers with annular gain media", IEEE J. of Quantum Electronics, 30 (6), 1441 - 1447 (1994)

[12] Schlüter, H., "Laser resonator", German patent DE 5980549 (1997)

[13] Giesen, A., Brauch, U., Voss, A., Wittig, K., "Laser amplifying system”, German patent DE 4132063 (1994) 
[14] Giesen, A., Hügel, H., Voss, A., Wittig, K., Brauch, U., Opower, H., "Diode-pumped high-power solid-state laser:concept and first results with Yb:YAG", OSA Proceedings on Advanced Solid State Lasers Vol. 20, 91 (1994)

[15] Giesen, A.,Hönninger, C., Zhang, G., Keller, U., "Femtosecond Yb:YAG laser using semiconductor saturable absorbers", OPTICS LETTERS, 20 (23), 2402-2404 (1995)

[16] Brauch, U., Giesen, A., Karszewski, M., Stewen, C., Voss, A.: "Multiwatt diode-pumped Yb:YAG thin disk laser continuously tunable between 1018 and 1053 nm", OPTICS LETTERS, 20 (7), 713-715 (1995)

[17] Karszewski, M., Brauch, U., Contag, K., Erhard, S., Giesen, A., Johannsen, I., Stewen, C., Voss, A., "100 W TEM operation of $\mathrm{Yb}: \mathrm{YAG}$ thin disk laser with high efficiency", OSA Trends in Optics and Photonics, Advanced SolidState Lasers, W. A. Bosenberg and M. M. Frejer, Eds. Washington, DC: Opt. Soc. Amer., vol. 19, 125 (1998)

[18] Stewen, C., Contag, K., Larionov, M., Giesen, A., Hügel, H., “A 1-kW CW Thin Disk Laser”, IEEE J. of Quantum Electronics, 6 (4), 650-657 (2000)

[19] Giesen, A., Speiser, J., "Fifteen Years of Work on Thin-Disk Lasers: Results and Scaling Laws", IEEE J. of Quantum Electronics, 13 (3), 598-609 (2007)

[20] R. Paschotta, "Power scalability as a precise concept for the evaluation of laser architectures", open access paper on arXiv.org, see www.arxiv.org/abs/0711.3987

[21] Garbuzov, D., Z., Antonishkis, N., Y., Bondarev, A., D., Gulakov, A., B., Zhigulin, S., N., Katsavets, N., I., Kochergin, A., V., Rafailov, E., V. "“High-power $0.8 \mu \mathrm{m}$ InGaAsP-GaAs SCH SQW lasers”, IEEE J. of Quantum Electronics, 27 (6), 1531 - 1536 (1991)

[22] Garbuzov, D., Z., Abeles, J., H., Connolly, J., C., "High Power Semiconductor Laser Diode”, United States Patent $5,818,860(1995)$

[23] Garbuzov, D., Z., Maiorov, M., Harvey, M., Al-Muhanna, A., Mawst, L., Botez, D., Connolly, J., "Super High Power Operation of $0.98 \mu \mathrm{m} \mathrm{InGaAs}(\mathrm{P}) / \mathrm{InGaP} / \mathrm{GaAs}$ Broadened Waveguide Separate Confinement Helerostructure Quantum Well Diode Lasers", Proc. SPIE Photonics West '99, Physics and Simulation for Optoelectronic Devices VI, Vol. 3625, pp. 100-107, San Jose, CA Jan. 23-29, 1999.

[24] Garbuzov, D., Menna, R., Komissarov, A., Maiorov, M., Khalfin, V., Tsekoun, A., Todorov, S., Connolly J., "1400 - $1480 \mathrm{~nm}$ ridge wavelength pump lasers with 1 watt CW output power for EDFA and Raman amplification", Optical Fiber Communication Conference postdeadline papers, OSA Technical Digest Series, Optical Society of America, Washington, D.C., 2001

[25] Product brochure, JOLD-x-CANN-1L, Jenoptik Laserdiode, www.jold.de

[26] Jansen, M., et al, "High performance laser diode bars with aluminum-free active regions", Optics Express, 4 (1), 3 $11(1999)$

[27] He, X., Patel, R., Ovtchinnikov, A., Kanskar, M., Yang, S., Harrison, J., "Record high CW power for monolithic diode arrays at $940 \mathrm{~nm}$ and 808nm“, Proc. of LEOS '99. IEEE, Vol. 1, 74-75 (1999)

[28] Gupta, S., Garcia, A., Srinivasan, S., He, X., Wilson, S., Harrison, J., Patel, R., "High average power density (0.2$0.65 \mathrm{~kW} / \mathrm{cm} 2$ ) diode laserstacks for $808 \mathrm{~nm}, 915 \mathrm{~nm}$ \& $940 \mathrm{~nm}$ wavelengths", Proc. of ISLC, 53-54 (1998)

[29] Mikulla, M.; Walther, M.; Kiefer, R.; Jandeleit, J.; Brandenburg, W.; Loosen, P.; Poprawe, R.; Weimann, G., "High-power diode laser bars $>250$ W", Proc. of LEOS 2000. IEEE, Vol. 1, (2000)

[30] Schröder, D., Meusel, J., Hennig, P., Lorenzen, D., Schröder, M., Hülsewede, R., Sebastian, J., "Increased power of broad area lasers $(808 \mathrm{~nm} / 980 \mathrm{~nm})$ and applicability to $10 \mathrm{~mm}$-bars with up to 1000 Watt QCW ", Proc. of SPIE Vol. $6456,64560 \mathrm{~N},(2007)$

[31] Hostetler, J., L., Jiang, C., L., Negoita, V., Vethake, T., Roff, R., Shroff, A., Li, T., Miester, C., Bonna, U., Charache, G., Schlüter, H., Dorsch, F., "Thermal and strain characteristics of high power $940 \mathrm{~nm}$ laser arrays mounted with AuSn and In solders", Proc. SPIE Vol. 6456, San Jose, USA, 645602 (2007) 